\title{
Advanced Composite Materials in Cryogenic Propellant Tank
}

\section{(CRYO-TANK)}

\author{
S. Prasanraj \\ B. Sreejish \\ Y. Vincy Jarome \\ Department of Aeronautical Engineering, \\ Hindusthan Institute of Technology, Coimbatore-32, India
}

\author{
Dr. K. P. Dhanabalakrishnan \\ (Professor \& Head) \\ Department of Aeronautical Engineering, \\ Hindusthan Institute of Technology, \\ Coimbatore-32, India
}

\begin{abstract}
The reinforced resin matrix of carbon composite materials are being utilized in the aerospace industry over metallic cryo-tanks as the methods of diminishing vehicle weight. Carbon fibre reinforced composites (CFRC) dominates in high strength-to-weight and high stiffness-toweight proportions. The usage of textile-composites in cryogenic propellant tanks (cryo-tank) for upcoming space heavy-lift launch vehicles could incredibly lessen the vehicle's weight by supplanting the indistinguishably sized cryo-tanks developed of typical metallic materials. Although the CFRC composites producing process is not simple. In this work, a cryogenic tank is modeled in CATIA V5 and analysis is done by using ANSYS Workbench V16.2. After the analysis process, we had fabricated a scaled model of a 1:50 ratio. Here cryogenic propellant tank built by using textile composites (glass cloth-epoxy laminate) such as FR-4, G-10, S2-Glass/Epoxy composite materials. The main objective of the study conducted in this paper is to design cryogenic propellant tanks without metallic liner or insulator, thus further diminishing the overall weight of the cryo-tanks and sustaining in the service mechanical loads when exposed to the cryogenic temperatures $(77 \mathrm{~K})$.
\end{abstract}

Keywords - Cryotank, cryogenic composite materials, Structural analysis, composite fabrication, CFRC, cryogenic propellant tank, composite testing, liquid rocket propulsion, glass fibres, textile fibres, epoxy resin, cryogenic propulsion.

\section{INTRODUCTION}

Cryogenics is a word which originated from ancient Greek which means "Cold Producing" [1]. Cryogenic rocket propellant tank (Cryo-tank) is a pressure vessel for storing fuel or oxidizer of rocket stages. In many liquid rocket propulsion systems, Liquid Hydrogen is used as fuel for cryogenic stages. The Fuel is stored at extremely low temperature (below $-196^{\circ} \mathrm{C}$ ).

The upcoming space heavy-lift launch vehicles demands extremely excessive propellant mass fractions to obtain the designed performance set by the existing metallic tanks. This drives the design engineers to comprise light-weight materials into as many structures as it can possible. Cryogenic propellant fuel tanks (Cryo-tank) account for a huge share of the space launch vehicles, both structural and geometric mass when it comes to space. Approximately, $2 / 3^{\text {rd }}$ of the solid-mass of a space launch vehicle is the fuel and oxidizer tanks; by considering this we can reduce this weight proportion by implementing composites. This means we can take additional fuel and it can be utilized for further exploration [2-4].

The reinforced resin matrix of carbon composite materials (CFRC) are generally being used as a technique of lessening rocket weight. For upcoming space heavy-lift launch rockets and space investigation structures, advanced lightweight composites like glass fibres will be fully utilized in order to minimize vehicle weight, and CFRC in space applications demands enormous development to showcase robustness, durability, and high safety factor in order to improve the rate of tolerance. Moreover, the CFRC composite producing process is not as simple as metallic tank producing methods in existence [5].

In addition, composite structures could lessen manufacturing cost. Delta II faring, Delta III faring, and inter-stage production statics have shown that composite launch vehicle systems are low costlier than existed metal ones [3].

If propellants had been stored as pressurized gases, the size and mass of fuel tanks themselves could severely lower rocket efficiency. Therefore, to get the specified mass flow rate, the only alternative was to cool the propellants down to cryogenic temperatures below $77 \mathrm{~K}$ and $20 \mathrm{~K}\left(-196{ }^{\circ} \mathrm{C}\right.$ and $\left.-253{ }^{\circ} \mathrm{C}\right)$, converting them to liquid form. Hence, all cryogenic rocket engines are also, through definition, both liquid propellant rocket engines and hybrid rocket engines [1].

Different cryogenic fuel-oxidizer combinations had been tried; however the mixture of Liquid Hydrogen $\left(\mathrm{LH}_{2}\right)$ fuel and the Liquid Oxygen (LOx) oxidizer is one of the most widely used cryogenic fuel-oxidizer mixtures. Both additives are effortlessly and cheaply available, and when burned have one of the highest entropy releases with the aid of combustion, producing specific Impulse up to $450 \mathrm{~s}$, (effective exhaust velocity $4.4 \mathrm{~km} / \mathrm{s}$ ) [1].

\section{DESIGN \& MATERIAL SELECTION}

\subsection{DESIGN SELECTION}

Different designs of cryogenic propellant tank are read completely for powerful structure contemplations.

1) Cryogenic rocket propellant tank for putting away liquid hydrogen is taken as model. It is made of titanium composite (Ti-6Al-4V).The tank is Dome; span of tank is $2504 \mathrm{~mm}$. Length of propellant tank is 
$4894 \mathrm{~mm}$. Thickness of propellant tank is $6 \mathrm{~mm}$. These propellant tanks having a pressurization framework with titanium gas bottles as storage of helium [1].
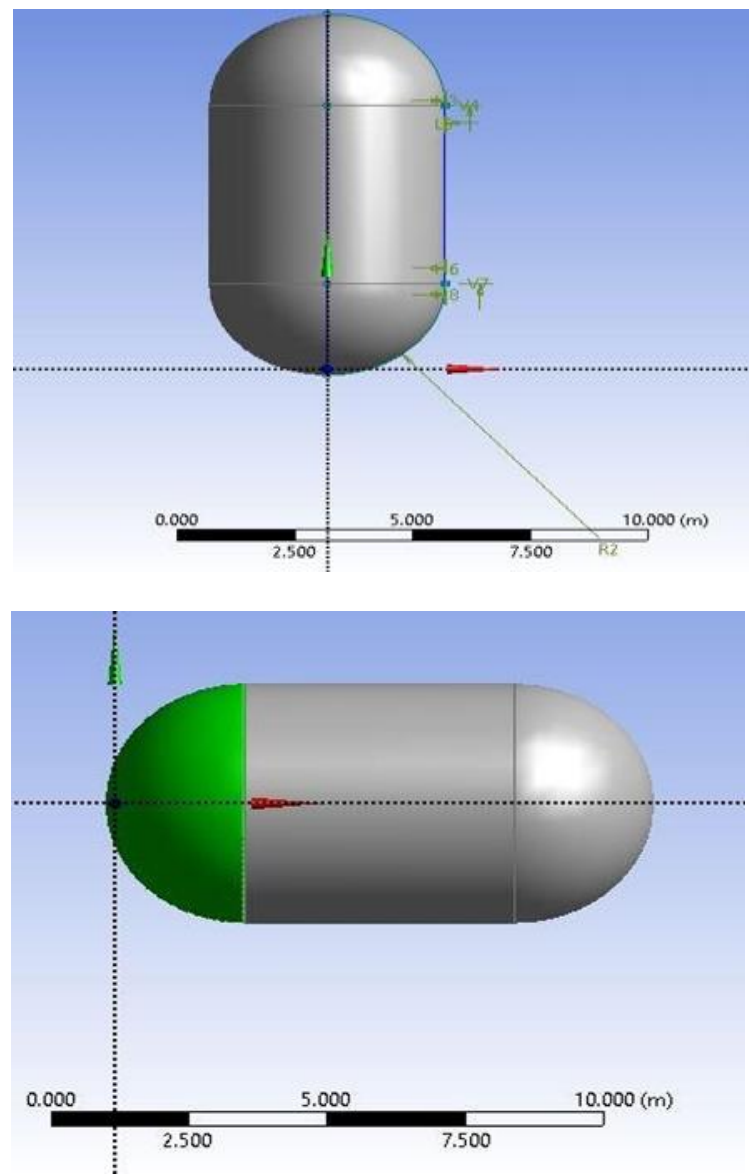

Figure 2.1.1a and 2.1.1b Existing design of metallic composite [1]

2) Liquid hydrogen tanks present an extreme challenge in engineering materials because of hydrogen permeability and cryogenic properties [3, 4]. Progress in composite cryogenic propellant tank development at McDonnell Douglas (MDA) started in 1987. MDA tackle the issue of hydrogen pervasion and cryogenic properties of composites effectively, and the composite LH2 tank for DC-XA was structured, developed, and manufactured. The tank was 8 feet $(2.43 \mathrm{~m})$ in breadth, 16 feet length $(4.88$ $\mathrm{m})$, built with IM7/8552 toughened epoxy material from Hercules. Automated fiber placement (AFP) was utilized $[6,7]$.

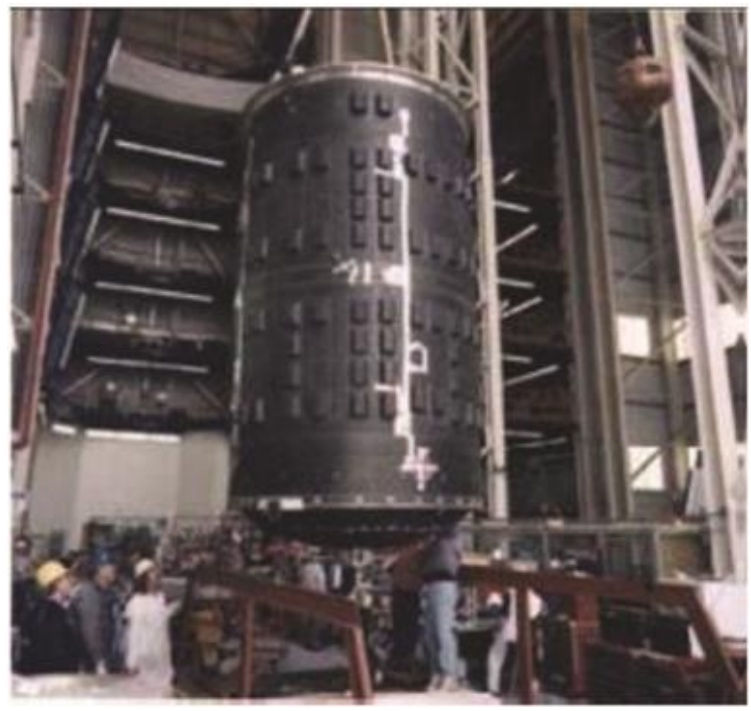

Figure 2.1.2 MDA cryo-tank [6, 7]

3) Lockheed Martin Space Systems Company (LM) is one of the global heads in enormous cryogenic propellant tank innovation [8]. The composite LH2 cryogenic tank for X33 vehicle was structured, created, and fabricated by LM and validated by NASA. The tank is 28.5 feet $(8.68 \mathrm{~m})$ in length, 20.0 feet $(6.09 \mathrm{~m})$ in breadth, and 14.0 feet $(4.26$ $\mathrm{m})$ in height $[9,10]$.

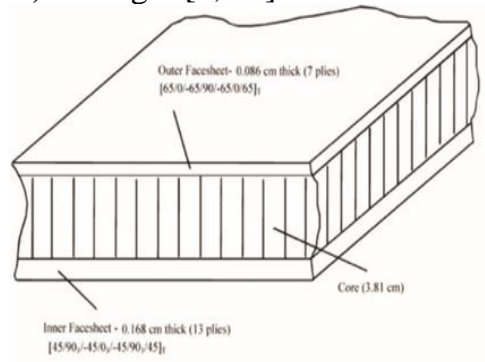

a

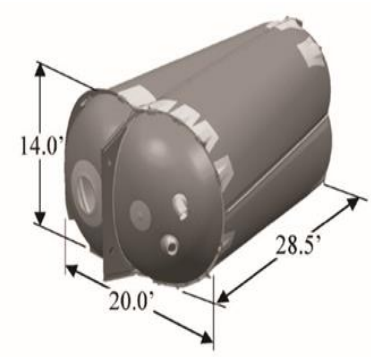

$\mathrm{b}$
Fig 2.1.3a Sandwich construction and Fig 2.1.3b LH2 cryo-tank [9, 10]

4) Northrop Grumman designed, created, and manufactured a barrel composite LH2 cryo-tank for Space Launch Initiative Composite Cryo-tank Program. The testing included the mimicked load cases close to a cryogenic propellant rocket launch. The composite cryotank is $1.8 \mathrm{~m}$ width and $4.5 \mathrm{~m}$ length, was loaded up with liquid hydrogen. The tank was likewise dependant upon an internal pressure load of $827 \mathrm{KPa}$ (120 psi.) and an axial load along the vertical axis of a launch vehicle. The composite propellant tank was one fourth of the scaled size of a typical reusable launch vehicle cryo-tank [11-13]. 


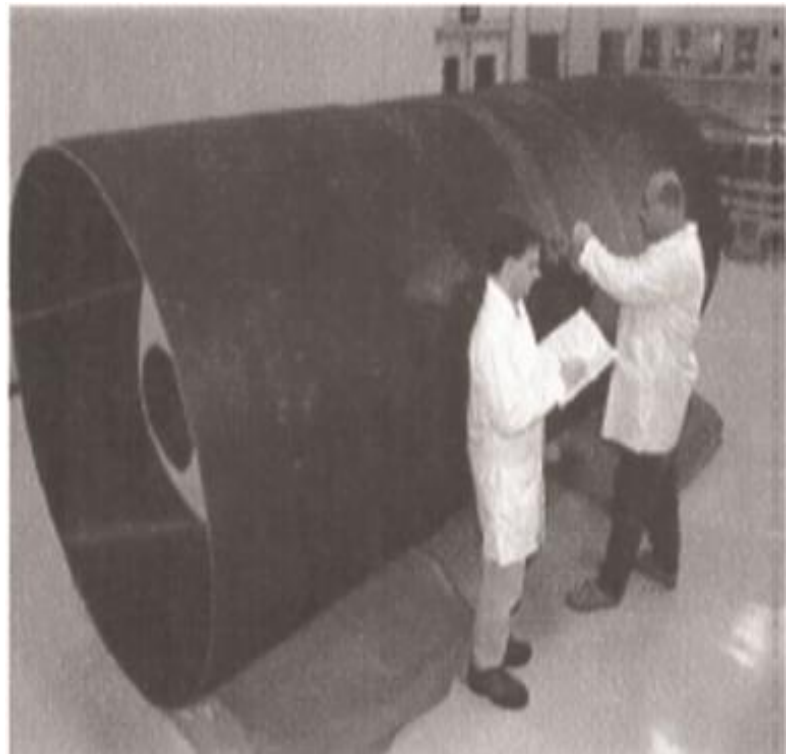

Fig 2.1.4 Northrop Grumman Cryo-tank [12]

5) The NASA group built up a metallic aluminium combination cryo-tank idea for correlation with IM7/977-2 composite concepts with the similar dimensions. The tanks were made of Cytec's CYCOM 5320-1 out-of-autoclave (OOA) pre -preg, hybrid laminate was utilized, using a blend of thick plies $(145 \mathrm{~g} / \mathrm{m} 2)$, which can be set moderately, rapidly and empower enormous (up to $10-\mathrm{m}$ breadth) cryo-tank manufacture, and thin plies (70 g/m2), which make a minute crack-resistant laminate that counteracts hydrogen permeation $[14,15]$.

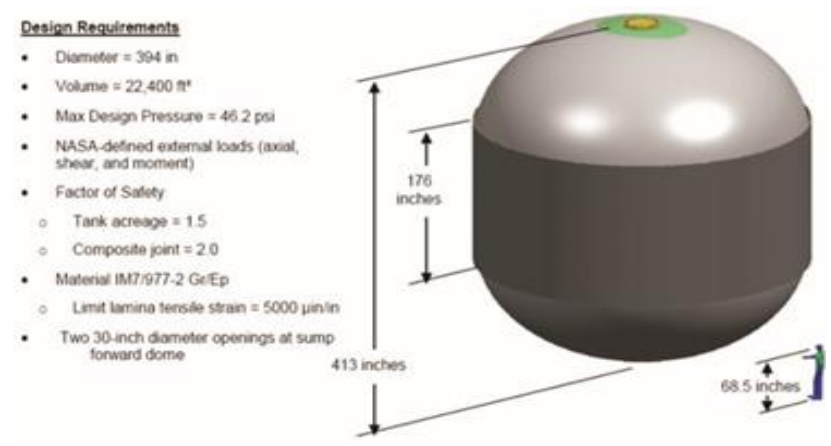

Fig 2.1.5 NASA cryo-tank design [2]

Various designs of cryogenic propellant tank are studied thoroughly for effective design considerations.

The design requirements for cryogenic propellant such as mechanical and thermal loads are taken into account to select the better design.

Above all the existing design considerations the NASA cryo-tank considered as the effective design for further analysis and fabrication process.

\subsection{MATERIAL SELECTION:}

Metallic alloys are previously used as cryogenic tank materials. There may be of different metal compositions of effective properties. The variable material properties of higher grade Titanium alloy are considered for the design of propellant tank [1].

\begin{tabular}{|c|l|}
\hline MATERIAL & Ti-6Al-4V \\
\hline Titanium & $90 \%$ \\
\hline Aluminium & $6 \%$ \\
\hline Vanadium & $4 \%$ \\
\hline Poisson's ratio & 0.340 \\
\hline Young's modulus & $115-120 \mathrm{GPa}$ \\
\hline
\end{tabular}

Table 2.2.1 Metallic cryo-tank composition [1]

Al-Li alloys are most usually utilized cryogenic tank materials where the weight consideration necessity is high. Past research in regards to the utilization of composite materials as cryogenic propellant tank materials majorly dealt with thermal cycling of uni-directional composites and their damage behavior and permeability under fatigue thermal loads. The mechanical and structural properties of uni-directional E-glass fiber/epoxy and Carbon fiber/epoxy laminate at cryogenic temperature (below $77 \mathrm{~K}$ ) and studied helium permeation on woven E-glass texture composites [16].

It examined hydrogen fuel tank with foam core and multilayer insulations (MLI) along with aluminum tank divider and composite fairing. Investigated aluminumlined, fiber wrapped cryogenic hydrogen storage tank at various temperature and pressure cycles [16].

G-10CR is a pre-preg, which is currently being used as cryogenic blankets. The internal laminar shear strength (ILSS) of G-10CR glass-cloth or FR-4 fibre/epoxy laminates at room temperature, $77 \mathrm{~K}\left(-196^{\circ} \mathrm{C}\right)$ and $4 \mathrm{~K}(-$ $269^{\circ} \mathrm{C}$ ) temperatures and found a little bit increase in ILSS with reduced temperature. Further, examined the impact of cryogenic molding of woven carbon/epoxy laminates and found a decrease in ILSS at a higher fiber volume fraction [16].

S2-Glass clothes are widely used glass fibres in cryogenic applications. Max. Service temperature $=590 \mathrm{~K}$. Min. service temperature $=4 \mathrm{~K}$.

So we have selected S2-glass/epoxy for further analysis and fabrication process.

\subsection{FE Modeling:}

\section{III.COMPUTATIONAL ANALYSIS}

Generate FE model based on the CAD model with desired mesh size as suitable based on iterations .The sequence of analysis is as listed below

a. Input study \& CAD model finalization

b. Geometry import, repair and simplification

c. Discretize the model as per meshing standards and quality parameter

d. Apply applicable loads and constraints ensuring proper contacts and connections are generated by the FEA solver (Ansys WB)

e. Static structural analysis to evaluate the von Mises stress, shear stress and total deformation for the designed configuration.

f. Check solution convergence and post-processing for accurate results. 
Mesh Plot:

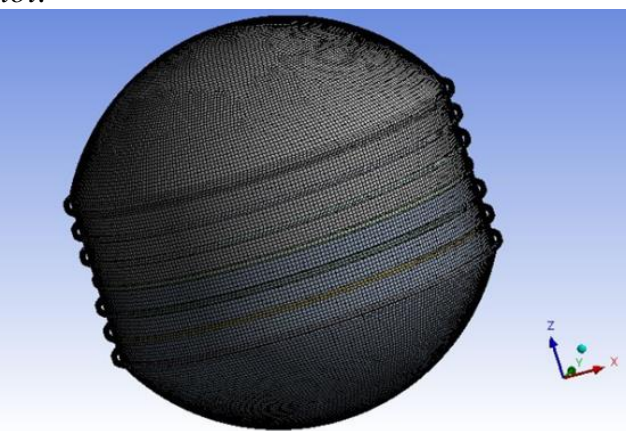

Fig 3.1.1 Mesh plot of cryo-tank along with stiffeners

\section{FEA CASES \& RESULTS}

\section{CASE 1}

Thermal load $=-196^{\circ} \mathrm{C}$ applied as temperature on the inner surface of the Propellant tank.

Fixed supports:

1. Fixed at the centre of the structure.

2. Stiffener of $100 * 36 \mathrm{~mm}$ provided at the centre of the structure.

3. 6 T-shaped stiffeners with web $-100 * 25 \mathrm{~mm}$ thick and flange- $150 * 25 \mathrm{~mm}$ are provided along the shell.

4. Self-weight: gravity load.

Pressure $=8.27$ bar applied as pressure on the inner surface of the Propellant tank.

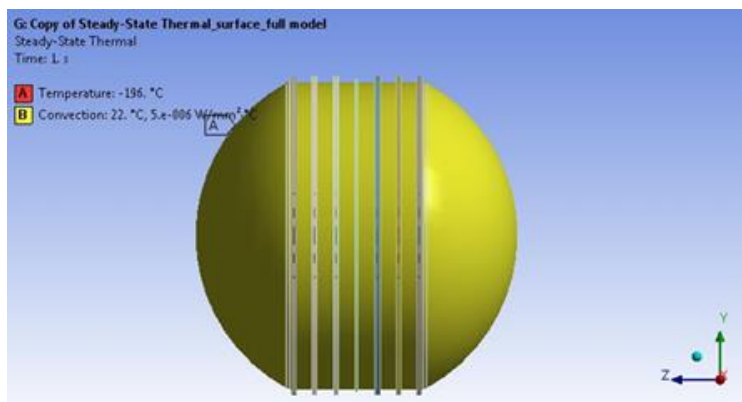

Fig.4.1.1 Internal thermal load

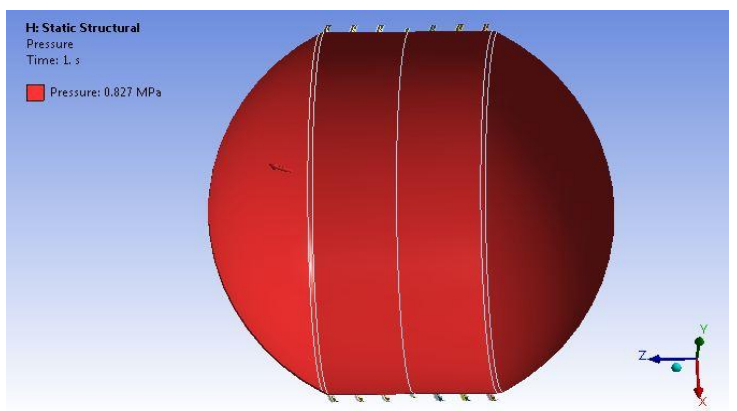

Fig 4.1.2 Internal pressure

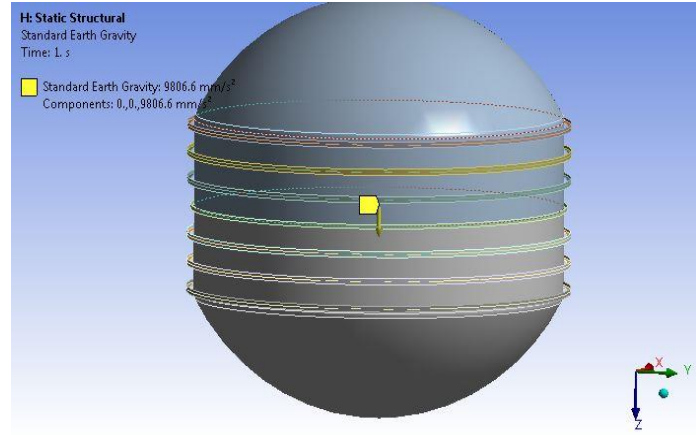

Fig 4.1.3 Boundary condition due to gravity

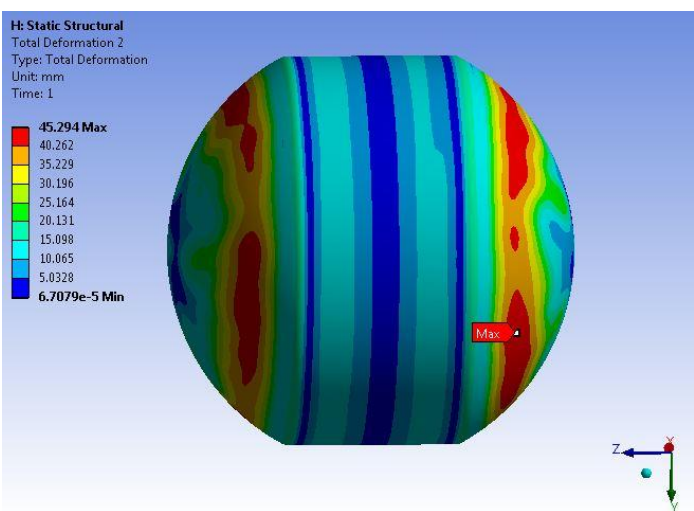

Fig 4.1.4 Total deformation in actual model

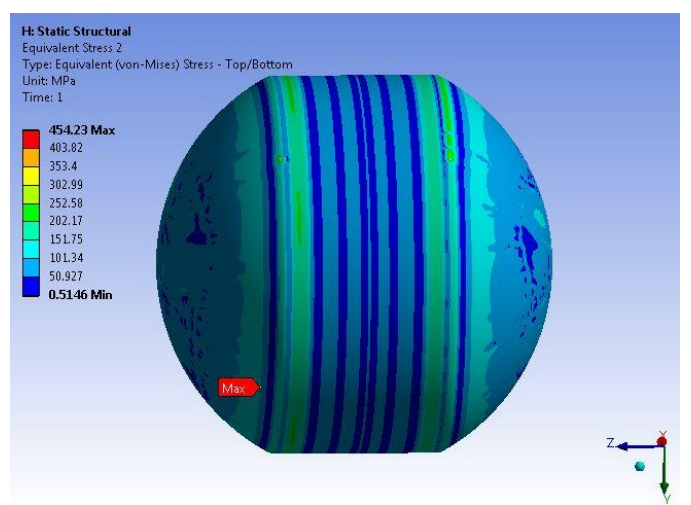

Fig 4.1.5 Equivalent stress in actual model

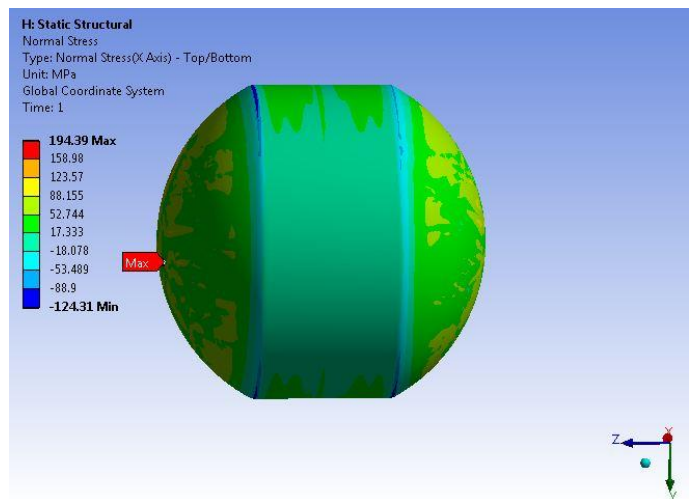

Fig 4.1.6 Normal stress in $X$ - direction 


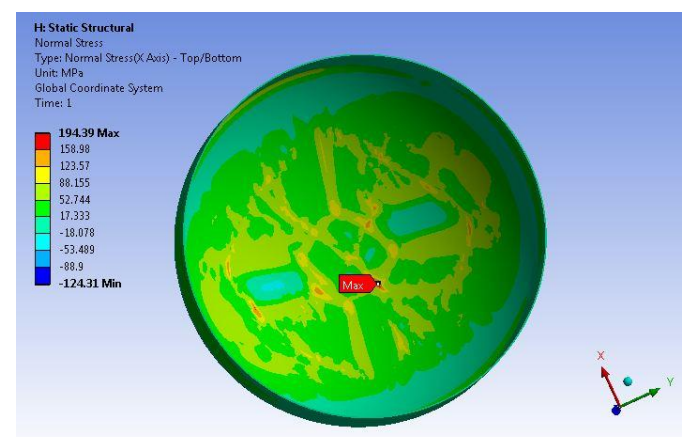

Fig 4.1.7 Zoomed plot for Normal stress- $X$

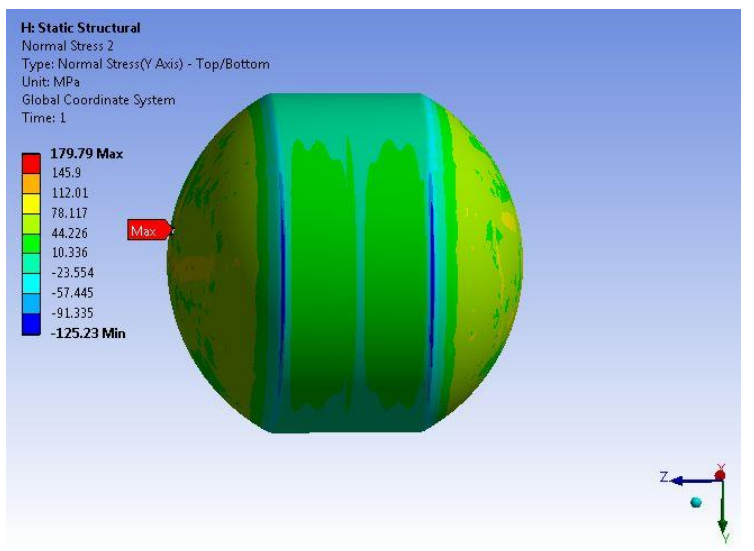

Fig 4.1.8 Normal stress for $Y$ - direction

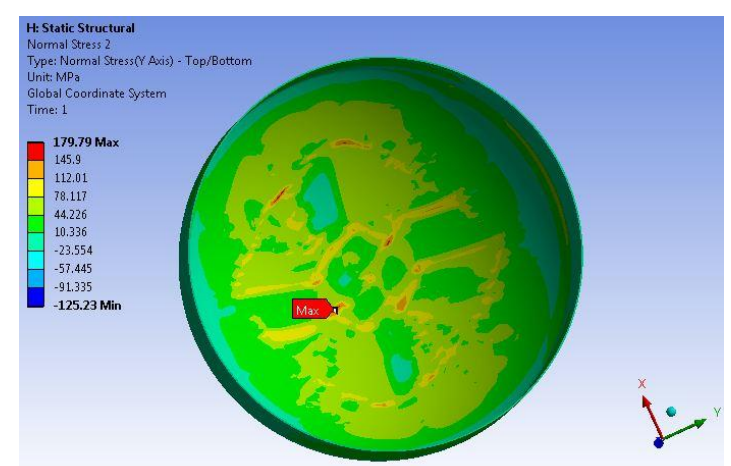

Fig 4.1.9 Zoomed plot for Normal Stress-Y

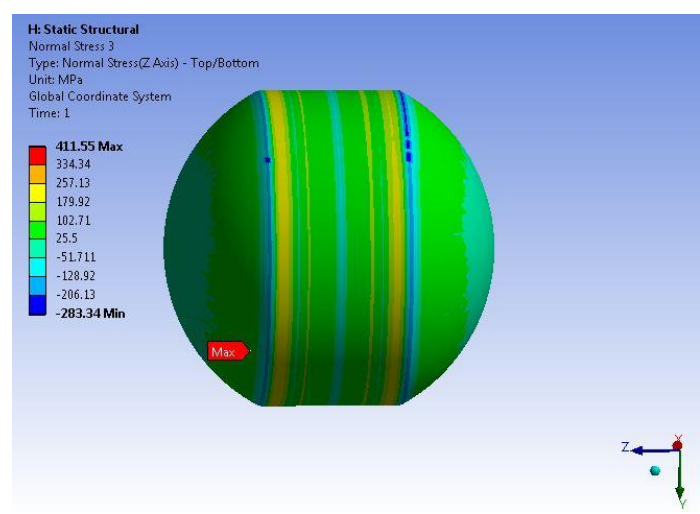

Fig 4.1.10 Normal Stress on Z- direction

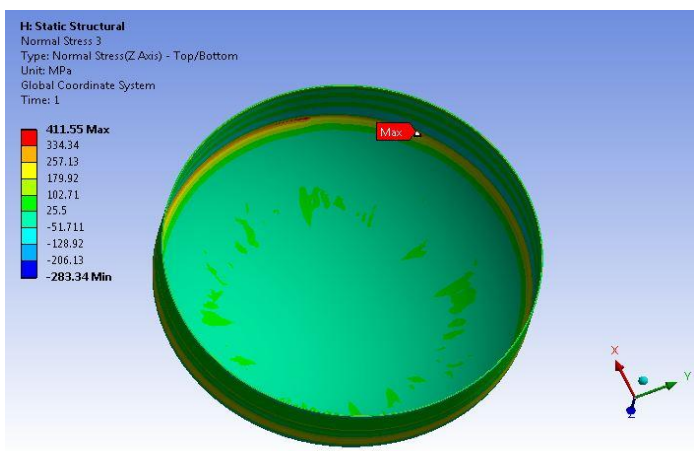

Fig 4.1.11 Zoomed plot on Normal stress-Z

\section{Observations:}

The total deformation plot, equivalent Von-Mises stress plot, orthotropic X, Y and Z -Normal stress plots are studied and it is concluded that the design and material selection can withstand such service mechanical loads.

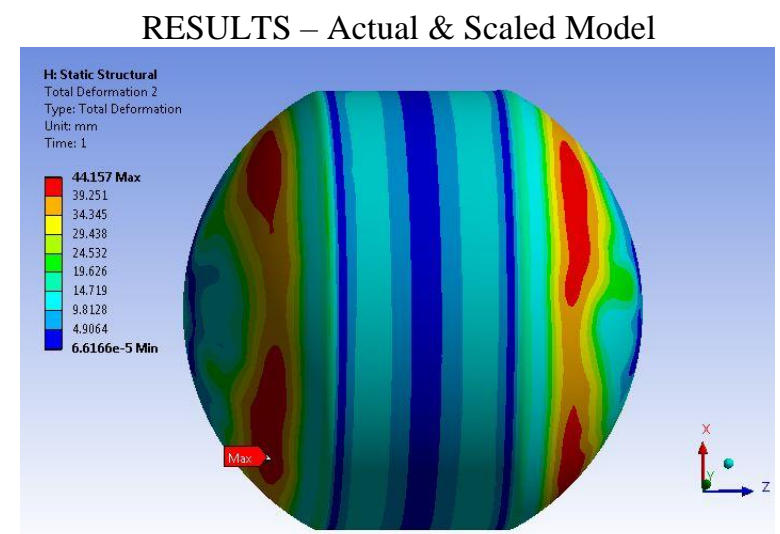

Fig 4.1.12 Total deformation

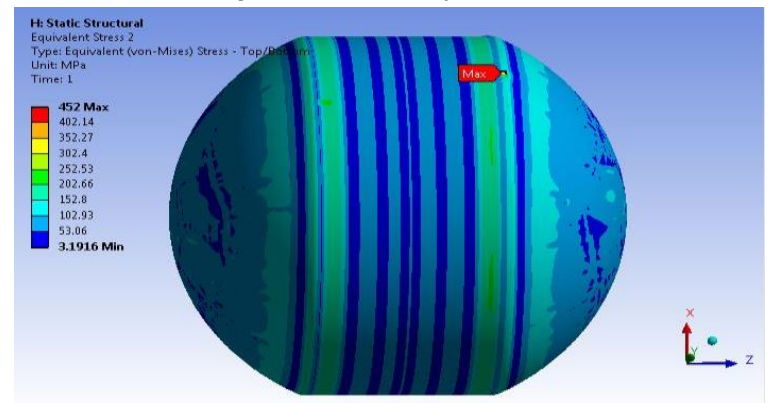

Fig 4.1.13 Equivalent stress

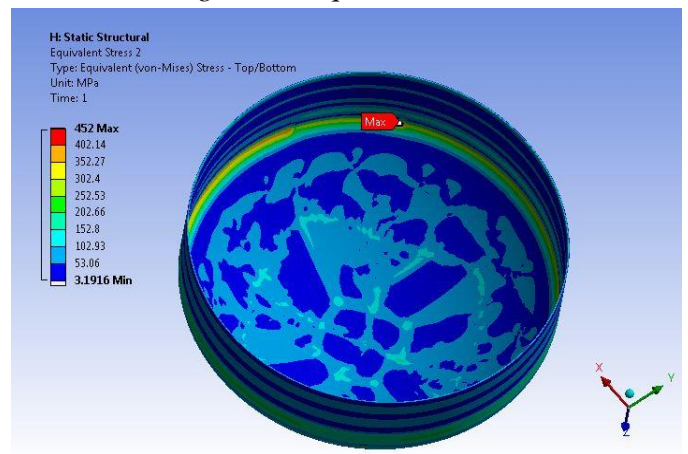

Fig 4.1.14 Zoomed plot on Equivalent stress 


\section{CASE 2}

Scaled model (1:50) same temperature applied on the inner surface of the propellant tank apply same case 1 boundary conditions and pressure values.

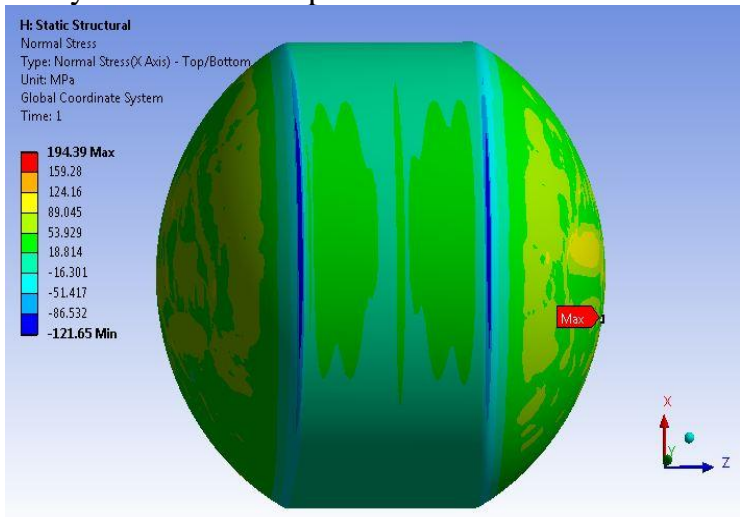

Fig 4.2.1 Normal stress on $X$-direction

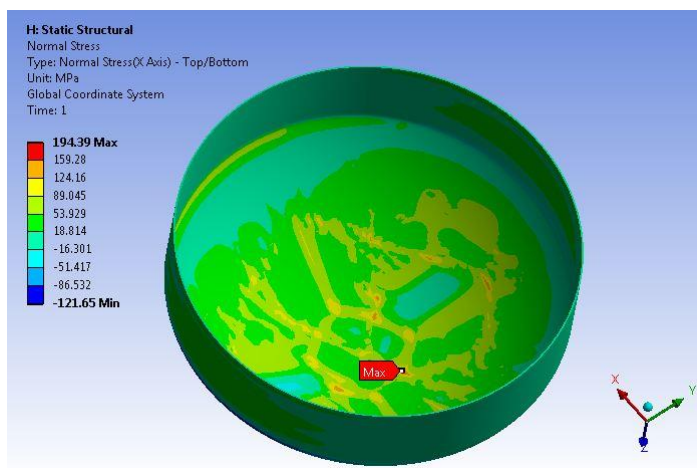

Fig 4.2.2 Zoomed plot on Normal stress- $X$

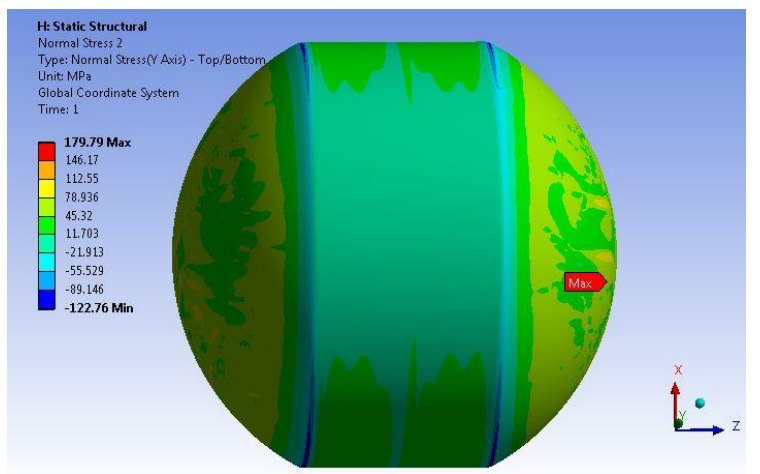

Fig 4.2.3 Normal stress on $Y$ - direction

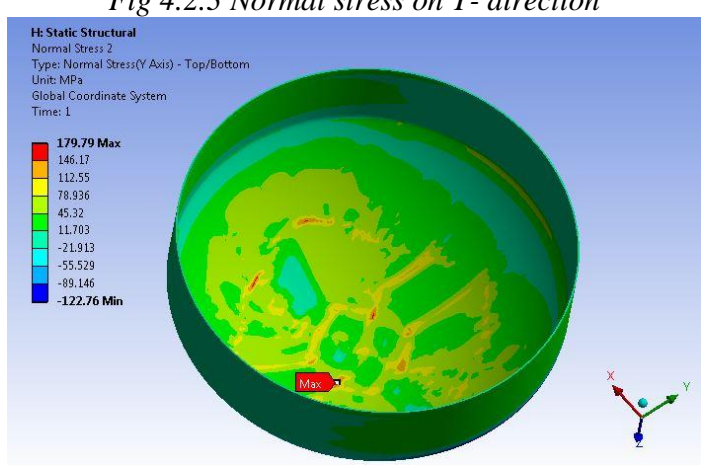

Fig 4.2.4 Zoomed plot on Normal stress- $Y$

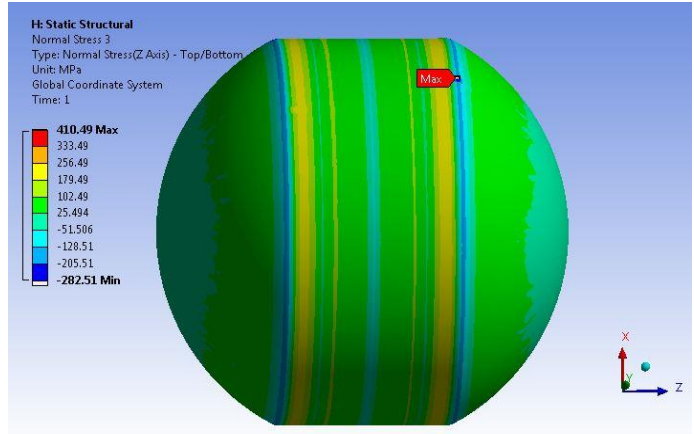

Fig 4.2.5 Normal stress on Z-direction

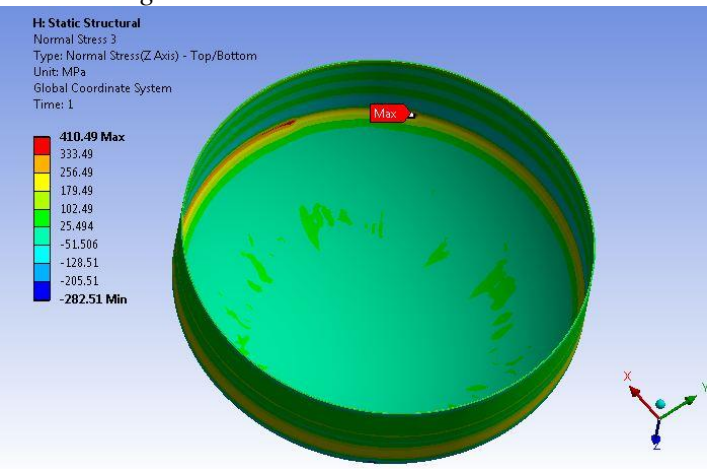

Fig 4.2.6 Zoomed plot on Normal stress-Z

\section{Observations:}

The total deformation plot, equivalent Von-Mises stress plot, orthotropic $\mathrm{X}, \mathrm{Y}$ and $\mathrm{Z}$-Normal stress plots are studied and it is concluded that the design and material selection for scaled model can withstand such service mechanical loads.

\section{FABRICATION:}

\subsection{Introduction:}

There are various techniques for manufacturing composite parts. A few strategies have been obtained (injection molding, for instance), however many were created to meet explicit structure or manufacturing challenges. Selection of a technique for a specific part, in this manner, will rely upon the materials, the part structure and end-use or application.

Composite manufacture reforms include some type of molding, to shape the resin and reinforcement. A mold tool is required to employ the unformed resin /fiber blend its shape prior to and during cure. The most essential manufacturing method for thermo-set composites is handlayup, which typically consists of laying dry fabric layers, or "plies," or pre-preg plies, by hand onto a tool to produce a laminate stack (a number of plies stacked together). Resin is deployed to the dry plies after layup is complete (e.g., by means of resin-infusion). There were many curing methods are available. The most commonly used technique is simply allowing cure to occur at room temperature. Cure can be stimulated, however, by applying heat, ordinarily with an oven, and pressure rise, by methods for a vacuum. 
Some superior thermo-set parts require heat and high solidification pressure to cure-conditions that require the utilization of an autoclave. Autoclaves, for the most part, are expensive to purchase and operate. Manufacturers that are carried by autoclaves normally cure a number of thermo-set parts simultaneously. Computer framework monitors and control autoclave temperature, pressure, vacuum and inert-atmosphere, which permits unattended or potentially remote supervision of the cure process and amplifies proficient utilization of the techniques.

\subsection{Process:}

VARTM is abbreviated as Vacuum-Assisted Resin Transfer Molding. It refers to a variety of related processes that represent the fastest-emerging new molding technology. The primary contrast between VARTM-type processes and RTM is that in VARTM, resin is drawn into a pre-form by means of a vacuum only, rather than pumped in under pressure. VARTM does not require high temperature of thermal or pressure loads. For that reason, VARTM operates with affordable tooling, making it possible to inexpensively produce gigantic, complex parts in single shot. In the VARTM process, fiber reinforcements are placed in a one-sided mold, and a cover (typically a vacuum-assisted plastic bagging film) is placed over the top of the mold to frame a vacuum-tight seal.

The resin typically enters the structure through deliberately set ports and feed lines, termed as "manifold." It is drawn by vacuum through the reinforcements by methods for a series of planned channels that encourage wet out of the fibers. Fiber composition in the completed part can run as high as 70 percent. Current applications incorporate marine, ground transportation and foundation parts [16].

\subsection{Tools:}

The fabrication process can be started after checking up with all required tools. The tools used for fabrication is given below,

1. Mould.

2. Resin transfer brush.

3. Tool holder.

4. Vacuum bags with arresters.

5. Vacuum cylinder.

6. Joggle for clamping.

7. Peel ply.

8. Breather - Bleeder.

9. Driller.

10. Bonding resin clamps.

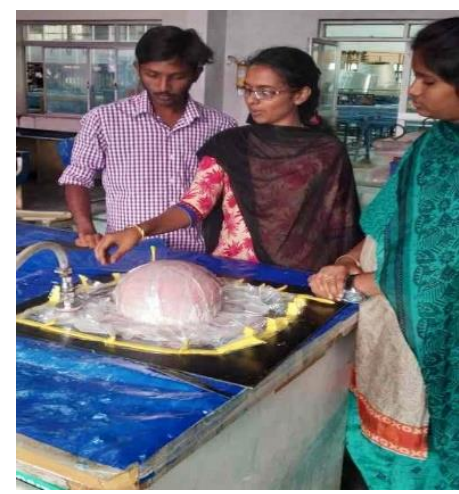

Fig 5.3.1 a First half mold in vacuum pressure bag

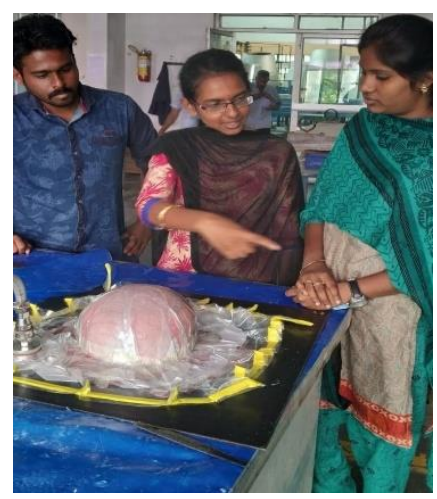

Fig 5.3.1b Second half mold in vacuum pressure bag

\subsection{Fabrication of Model:}

Fabrication is done by using VARTM (Vacuum Assisted Resin Transfer Moulding) process. First a mould is preferred for its internal dimension. The mould is first finely polished with mention polish (putty). The mould is made like a half model, by that half mould we place each laminas of S2-Glass/Epoxy over it wrapped in a unidirectional lamina (S2-Glass/Epoxy UD).

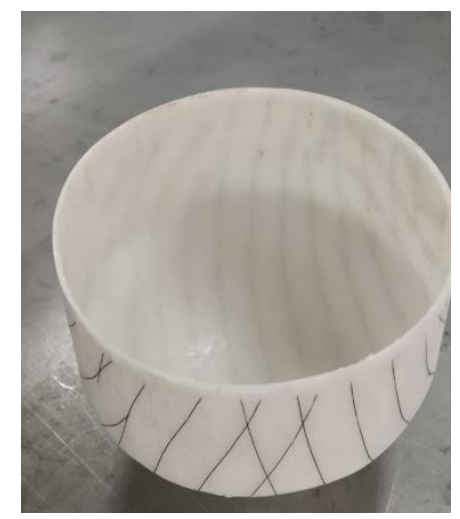

Fig 5.4.1a Finished first half mold

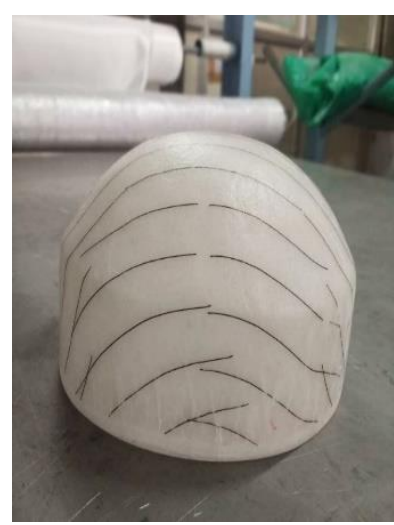

Fig 5.4.1b Finished second half mld
First one half part of the tank is made and it can be attached with the breather bleeder and peel ply over the finished laminate. The breather bleeder removes the additional resin over the laminate while kept in a vacuum pressure. It is kept in a vacuum pressure of $450 \mathrm{psi}$ about 4 hours and it is kept to cure for 24 hours in the tool after removing the vacuum bag.

Then another part was made by fixing a joggle on the bottom of it. This joggle helps to fix the two halves. It can be further fixed with the bonding resin- EC-9323 in 100:27 ratios. Before it 4 holes of $1 / 4$ " inch were made for fixing the inlet, outlet and other valves jointed with the check nuts on the both side (inner \& outer) and the bulk-head connectors thoroughly sealed by the bonding resin to avoid further leakages. 


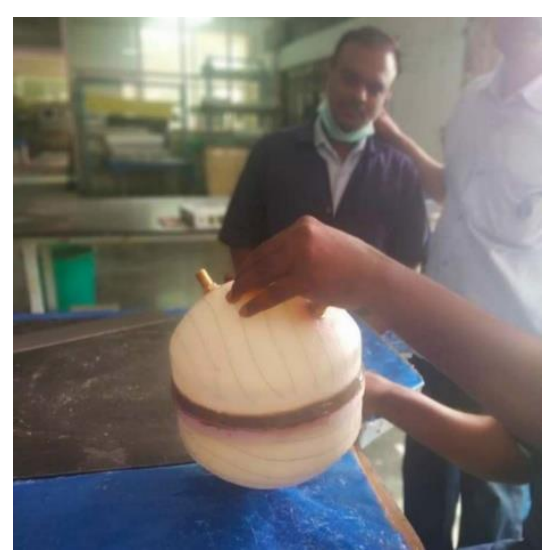

Fig 5.4.2 Fabricated 1:50 scaled model

The full mould was again wrapped uni-directionally for remaining $3.5 \mathrm{~mm}$ thickness then attached with peel ply and breather bleeder and kept in a vacuum pressure about 4 hours and curing is don on the tool about 24 hours after removing the vacuum bag.

The breather bleeder and peel ply placed over the model is then removed if additional wrapping is required for design considerations. We can't wrap the fibres and resin over the model without peeling the peel ply over it.

Finishing and smoothening of surface is done after the curing is finished. And visual inspection is primarily done on the scaled model. The finished model is then processed to the paint shop for further painting of scaled model of grey and black color.

\section{VI .TESTS CARRIED OUT AFTER FABRICATION:}

After fabrication of the scaled model series of tests have been conducted to conclude the results. They are,

1. Visual inspection.

2. Leak test.

3. Preliminary pressure test.

4. Short beam shear test.

5. Flexural test.

6. Tensile test.

7. In-plan shear test.

8. Full pressure test (120 psi).

\begin{tabular}{|c|c|c|c|c|c|c|}
\hline \multirow{3}{*}{$\frac{\text { IIT }}{3155}$} & \multirow{3}{*}{$\frac{\sum^{3}}{\mathrm{r}=\mathrm{s}}$} & \multirow{3}{*}{\multicolumn{3}{|c|}{ 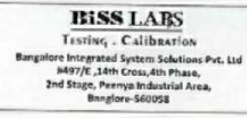 }} & \multirow{3}{*}{\multicolumn{2}{|c|}{$\begin{array}{c}\text { T/001 } \\
\text { BisS-TSR/17/04/114 } \\
\text { SRF No: TS141A16-1 } \\
\end{array}$}} \\
\hline & & & & & & \\
\hline & & & & & & \\
\hline \multicolumn{7}{|c|}{ Table 1.3: Test Results } \\
\hline Specimen ID & $\begin{array}{l}\text { Thickness } \\
(\mathrm{mm})\end{array}$ & $\begin{array}{c}\text { Width } \\
(\mathrm{mm})\end{array}$ & $\begin{array}{c}\text { E-modelus } \\
\text { (GPa) }\end{array}$ & $\underset{\text { Fareo(kN) }}{\max }$ & $\begin{array}{c}\text { Tensile } \\
\text { strength } \\
\text { (MPa) }\end{array}$ & \begin{tabular}{|c|}
$\begin{array}{c}\text { Strain to } \\
\text { tailure }(\%)\end{array}$ \\
\end{tabular} \\
\hline WEFT-TEN-1 & 1.034 & 12433 & 23.424 & 5.284 & 410.509 & 2372 \\
\hline WEFT-TEN-2 & 1.049 & 12620 & 22.913 & 5.287 & 399.334 & 2286 \\
\hline WEFT-TEN-3 & 1.056 & 12.663 & 23.108 & 5.178 & 387.093 & 2254 \\
\hline WEFT-TEN-4 & 1.050 & 12.313 & 22.910 & 5.289 & 408.914 & 2417 \\
\hline WEFT-TEN-5 & 1.050 & 12.640 & 23.312 & 5.068 & 381.851 & 2.128 \\
\hline Average & 1.048 & 12.534 & 23.133 & 5.221 & 397.620 & 2.291 \\
\hline Std Dev & 0.008 & 0.153 & 0.232 & 0.098 & 12.909 & 0.112 \\
\hline $\begin{array}{l}\text { Co off of } \\
\text { variation }\end{array}$ & 0.008 & 0.012 & 0.010 & 0.019 & 0.032 & 0.049 \\
\hline $\operatorname{Min}$ & 1.034 & 12313 & 22910 & 5.068 & 361.851 & 2.128 \\
\hline $\operatorname{Max}$ & 1.056 & 12.663 & 23.424 & 5.289 & 410.909 & 2.417 \\
\hline Range & 0.022 & 0.350 & 0.514 & 0221 & 29.058 & 0.289 \\
\hline
\end{tabular}

Tensile Test Results

\begin{tabular}{|c|c|c|c|c|c|c|}
\hline Specimen ID & $\begin{array}{c}\text { Thickness } \\
\text { (mm) }\end{array}$ & $\begin{array}{c}\text { Width } \\
\text { (mmm) }\end{array}$ & $\begin{array}{c}\text { E-modulus } \\
\text { (GPa) }\end{array}$ & $\operatorname{Max}_{\text {Forcof(kN) }}$ & $\begin{array}{l}\text { Tensilo } \\
\text { Strength } \\
\text { (MPa) }\end{array}$ & \begin{tabular}{|c} 
Strain to \\
fillure (\%)
\end{tabular} \\
\hline WARP-TEN-1 & 1.070 & 12.503 & 23.590 & 6.083 & 454.695 & 2.588 \\
\hline WARP-TEN-2 & 1.048 & 12.527 & 24.112 & 5.769 & 439.317 & 2.483 \\
\hline WARP-TEN-3 & 1.064 & 12.400 & 23.660 & 5.817 & 440.920 & 2.539 \\
\hline WARP.TEN-4 & 1.054 & 12437 & 24.055 & 5.731 & 437.242 & 2.478 \\
\hline WARP.TEN-5 & 1.091 & 12.693 & 22898 & 5.659 & 408.618 & 2443 \\
\hline Average & 1.065 & 12.512 & 23.663 & 5.812 & 436.158 & 2.506 \\
\hline Std Dev & 0.017 & 0.113 & 0.487 & 0.162 & 16.852 & 0.057 \\
\hline $\begin{array}{l}\text { Co eff of } \\
\text { varlation }\end{array}$ & 0.016 & 0.009 & 0.021 & 0.028 & 0.039 & 0.023 \\
\hline Min & 1.048 & 12.400 & 22.896 & 5.659 & 400.618 & 2.443 \\
\hline Max & 1.091 & 12.693 & 24.112 & 6.083 & 454.695 & 2.588 \\
\hline Range & 0.043 & 0.293 & 1.216 & 0.424 & 48.077 & 0.145 \\
\hline \multirow{3}{*}{$\frac{\text { III }}{3155}$} & \multirow{3}{*}{ (3) } & \multirow{3}{*}{\multicolumn{3}{|c|}{ 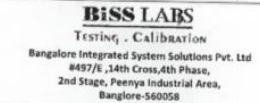 }} & \multicolumn{2}{|r|}{$T / 001$} \\
\hline & & & & & \multicolumn{2}{|c|}{ BisS-TSR/17/04/112 } \\
\hline & & & & & \multicolumn{2}{|c|}{ SRF No: TS141D16- } \\
\hline
\end{tabular}

Table 1.3: Test Results

\begin{tabular}{|c|c|c|c|c|c|}
\hline Specimen No & Short-beam Strength (MPa) & $\operatorname{Maxload}(\mathrm{N})$ & $\begin{array}{c}\text { Width } \\
\text { Avg (mm) }\end{array}$ & $\begin{array}{l}\text { Thickness } \\
\text { Avg (mm) }\end{array}$ & Length \\
\hline WARP-1 & 53.127 & 1365 & 6.396 & 3.012 & 18.033 \\
\hline WARP-2 & 49.321 & 1284 & 6.438 & 3.033 & 18.027 \\
\hline WARP-3 & 49.032 & 1264 & 6.442 & 3.001 & 18.041 \\
\hline WARP-4 & 54.171 & 1397 & 6.437 & 3.004 & 18.001 \\
\hline WARP-5 & 48.085 & 1237 & 6.441 & 2.995 & 18.068 \\
\hline Average & 50.747 & 1309.226 & 6.431 & 3.009 & 18.034 \\
\hline Std Dev & 2.713 & 68.261 & 0.019 & 0.015 & 0.024 \\
\hline $\begin{array}{l}\text { Co-eff. of } \\
\text { Variation }\end{array}$ & 0.053 & 0.052 & 0.003 & 0.005 & 0.001 \\
\hline Min & 48.085 & 1236.806 & 6.396 & 2.995 & 18.001 \\
\hline Max & 54.171 & 1396.578 & 6.442 & 3.033 & 18.068 \\
\hline Range & 6.085 & 159.772 & 0.046 & 0.038 & 0.067 \\
\hline
\end{tabular}

ILSS Test Results

\begin{tabular}{|c|c|c|c|c|c|}
\hline Spocimon No & Short-beam Strength (MPa) & Max load (N) & $\begin{array}{c}\text { Width } \\
\text { Avg (mm) }\end{array}$ & $\begin{array}{c}\text { Thickness } \\
\text { Avg ( } m \text { m) }\end{array}$ & Longth \\
\hline WEFT-1 & 51.194 & 1343 & 6.432 & 3.058 & 18.052 \\
\hline WEFT-2 & 51.755 & 1356 & 6.438 & 3.053 & 18.153 \\
\hline WEFT-3 & 51.988 & 1344 & 6.327 & 3.063 & 18.000 \\
\hline WEFT & 50.815 & 1327 & 6.438 & 3.042 & 18.049 \\
\hline WEFT-5 & 51.251 & 1294 & 6.172 & 3.068 & 18.316 \\
\hline Average & 51.401 & 1332.631 & 6.362 & 3.057 & 18.114 \\
\hline Std Dev & 0.469 & 24.079 & 0.116 & 0.010 & 0.126 \\
\hline $\begin{array}{c}\text { Oo-eff. of } \\
\text { Variation }\end{array}$ & 0.009 & 0.018 & 0.018 & 0.003 & 0.007 \\
\hline Min & 50.815 & 1293.905 & 6.172 & 3.042 & 18.000 \\
\hline Max & 51.988 & 136.417 & 6.438 & 3.068 & 18.316 \\
\hline Range & 1.173 & 62.512 & 0.266 & 0.026 & 0.316 \\
\hline
\end{tabular}



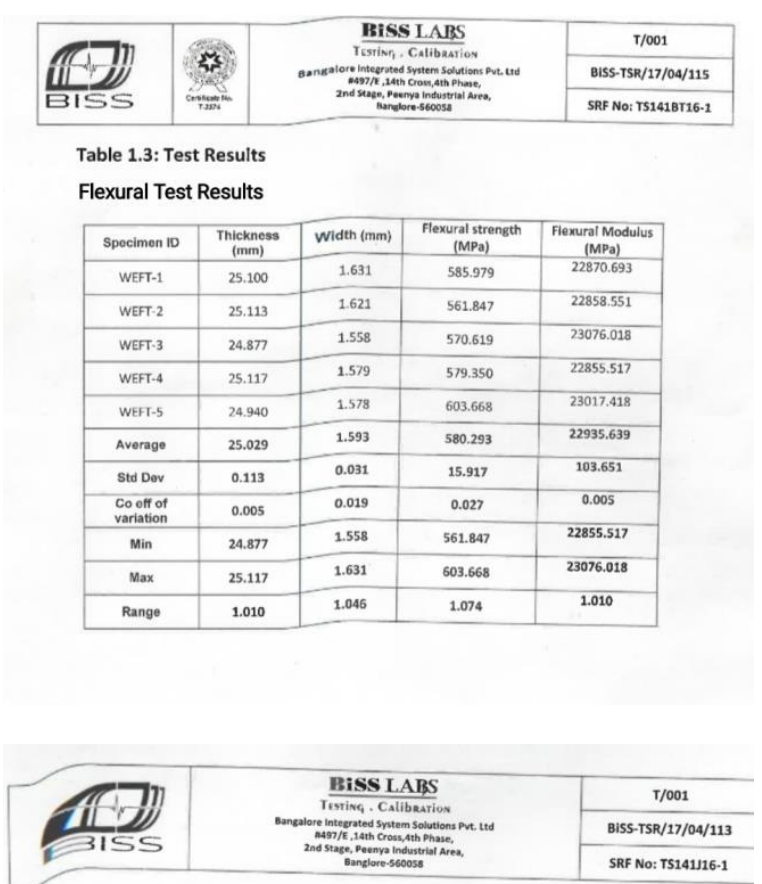

Table 1.3: Test Results
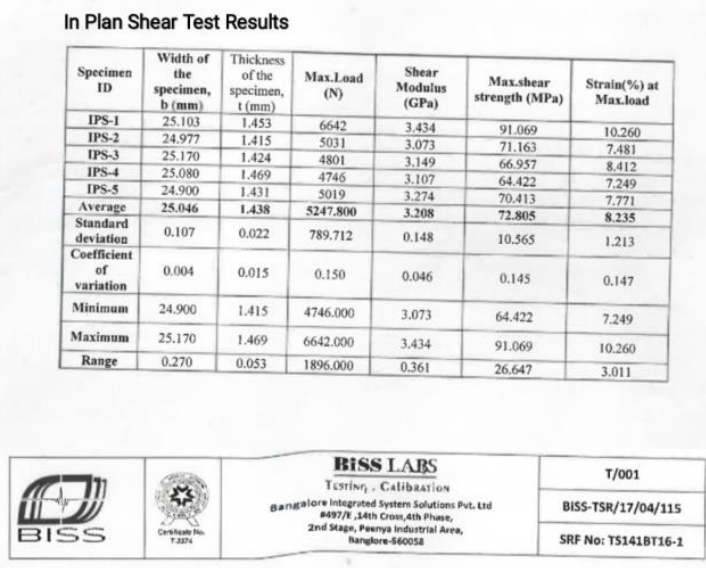

Table 1.3: Test Results Flexural Test Results

\begin{tabular}{|c|c|c|c|c|}
\hline Specimen 10 & $\begin{array}{c}\text { Thickness } \\
(\mathrm{mm})\end{array}$ & Width (mm) & $\begin{array}{l}\text { Flexural strength } \\
\text { (MPa) }\end{array}$ & $\begin{array}{l}\text { Flexurat Modulus } \\
\text { (MPa) }\end{array}$ \\
\hline WEFT-1 & 25.100 & 1.631 & 585.979 & 22870.693 \\
\hline WEFT-2 & 25.113 & 1.621 & 561.847 & 22858.551 \\
\hline WEFT-3 & 24.877 & 1.558 & 570.619 & 23076.018 \\
\hline WEFT-4 & 25.117 & 1.579 & 579.350 & 22855.517 \\
\hline Wefr-5 & 24.940 & 1.578 & 603.668 & 23017.418 \\
\hline Average & 25.029 & 1.593 & 580.293 & 22935.639 \\
\hline Stad Dov & 0.113 & 0.031 & 15.917 & 103.651 \\
\hline $\begin{array}{l}\text { Co off of } \\
\text { variation }\end{array}$ & 0.005 & 0.019 & 0.027 & 0.005 \\
\hline Min & 24.877 & 1.558 & 561.847 & 22855.517 \\
\hline Max & 25.117 & 1.631 & 603.668 & 23076.018 \\
\hline Range & 1.010 & 1.046 & 1.074 & 1.010 \\
\hline
\end{tabular}

\section{CONCLUSION \& FUTURE WORK}

- By comparing with the metallic cryo-tanks, composite cryo-tanks are highly effective in cryogenic exposure.

- Computational study results are the evidences for comparative studies of both actual and scaled model results.
- It doesn't require any insulator (metallic liner) thus by weight saving up to $40 \%$ over the metallic materials. But it needs to be vacuumized at the outer surface for sealing liquid propellants inside the cryo tank.

- The S2-Glass/Epoxy doesn't reacts with the alkalies was the other added advantage.

- Not only reducing weight it has high-strength to weight compare to the metallic cryo-tanks.

- Hence, it can be validated by conducting series of tests for further implementation process.

- The model we have made is to be completely sealed with a vacuum controlled container to arrest the liquid propellants inside the cryo-tank model.

- Additionally, we have about to fix some insulator materials for precautionary standards to avoid evaporation of liquid propellants.

- We assume G-10 CR, FR-4 of glass grade fibres which may have better results on cryogenic exposure. Then will implement those grades in future Cryo-tank technologies.

\section{Author Details:}

Prasanraj S, Sreejish B, Vincy Jarome $\mathrm{Y}$ and Dhanabalakrishnan KP (Professor and Head),

Department of Aeronautical Engineering, Hindusthan Institute of Technology, Coimbatore-32, India

\section{ACKNOWLEDGMENT}

First and foremost, we remember with gratitude, the blessing of Almighty who has given us health and necessary skill to complete the project work. We take this opportunity to express our sincere gratitude to our honorable Principal Dr. C. Natarajan for his kind encouragement for undergoing this project work.

We convey our heartiest and sincere thanks to our Head of the Department Dr. K. P. Dhanabalakrishnan, Professor and Head of Aeronautical Engineering to streamline our project work. We wish to register our heartiest thanks to project co-coordinator Mr. M. Moses Devaprasanna, Associate Professor, for his immediate approval and constant encouragement to bring out this project work.

We express our humble gratitude to our project guide Dr. K. P. Dhanabalakrishnan, Prof. \& Head, for his extended moral support in all possible ways to bring out this project work. We wish to register our heartiest thanks to Mr. Soundrarajan, Sr. General Manager, Mr. Tripathi, composite division Head, Ms. Nivetha, Business and Development executive, Mr. Ramesh, Design engineer, Mr. Krishna, Maintenance personnel, Mr. P. Yuvaraj, Production \& Control manager, Mr. Chandrappa and Mr. Nagaraj for their assistance and guidance fabrication works in TANEJA AEROSPACE and AVIATION LIMITED (TAAL), Hosur. We also express our thanks to Mr. Senthil Kumar, Analysis guide, TAALTech and Mr. Shino, HR \& Admin AAPL-TTRC, Bengaluru. We thank our beloved faculty members Mr. M. Harish, Mr. N. Maheswaran, Mr. V. Paramaguru, Mr. M. S. Prabhu, Mr. S. Tamil Selvan Dr. K. Mohammed Bak and our dear friends for the suggestion and constant support. 


\section{REFERENCES}

[1] "Design and model analysis of cryogenic rocket propellant tank" by L. Ramola, N. Sankareswaran, Regional centre of anna university, Tirunelveli, India.

[2] "Composite Cryotank Project Structures for Launch Vehicles" by John. V, Composites Australia Conference; 2013.

[3] "Composite Material Compatibility with Liquid Oxygen" by Robinson. MJ, Stoltzfus. JM, Owens. TN, AIAA-97-1107.

[4] "Composite Cryogenic Propellant Tank Development" by Robinson. MJ, AIAA-94- 1375-CP

[5] "The Application of Carbon Fiber Composites in Cryotank" by Hongfei Zheng, Xuesen Zeng, Jianbao Zhang and Hongjie Sun.

[6] "Acoustic Emission Monitoring of the DC-XA Composite Liquid Hydrogen Tank During Structual Testing", by Wilkerson C, NASA Technical Memorandum 108520.

[7] "Results of the DC-XA Program" by DumbacherD, AIAA-964317.

[8] "LH2 Tank Composite Coverplate Development and Flight Qualification for the X-33" by Wright. RJ, Roule. GM.

[9] "Debonding failure of sandwich-composite cryogenic fuel tank with internal Core pressure. Journal of Spacecraft and Rockets by" Glaessgen. EH, Reeder. JR, Sleight. DW, Wang. JT, Raju. IS, Harris CE; 2005.

[10] "X-33, Stepping Stone to Low Cost Access to Space" by NaftelC.

[11] "Cryogenic Composite Tank Design for Next Generation Launch Technology" by AbumeriGH, KosareoDN, RocheJM; AIAA.

[12] "Leak-proof Composite Tank Could Hoid Fuel or Astronauts, Flight International” by WarwickG, Sep 14-Sep 20, 2004;166,4951; ProQuest.

[13] "Composite fuel tank passes NASA tests", February 2004 REINFORCEDplastics.
[14] "NASA/Boeing Composite Launch Vehicle Fuel Tank Scores Firsts" by Knapschaefer. J, Composites World, 10/19/2017.

[15] "Composite Cryotank Technologies and Development 2.4 and 5.5m Out of Autoclave Tank Test Results" by Jackson JR, John V, John F.

[16] "Hybrid Textile Composites as Potential Cryogenic Tank Materials" by Md S. Islam, R. Avila, A. G. Castellanos, P. Prabhakar ,(University of Texas at El Paso, El Paso, TX, 79968, USA).

[17] "Low-Temperature Mechanical Properties of Glass/Epoxy Laminates" by R. P. Reed ${ }^{\mathrm{a}}$, M. Madhukar ${ }^{\mathrm{b}}$, B. Thaicharoenpornb, and N. N. Martovetsky ${ }^{\mathrm{c}}$

[18] "Final Results of Advanced Cryo-Tanks Research Project CHATT" developed at 6TH EUROPEAN CONFERENCE FOR AERONAUTICS AND SPACE SCIENCES (EUCASS) 2015 by Martin Sippel, Alexander Kopp Space Launcher Systems Analysis (SART), DLR, 28359 Bremen, Germany. David Mattsson Swerea SICOMP, Piteå, Sweden. Jonas Freund,Advanced Lightweight Engineering, Delft, The Netherlands. Ilias Tapeinos, Sotiris Koussios Delft University of Technology, Delft, the Netherlands

[19] "Advanced Composite Materials for Cold and Cryogenic Hydrogen Storage Applications in Fuel Cell Electric Vehicles" by U.S. Department of Energy Fuel Cell Technologies Office (FCTO) and Pacific Northwest National Laboratory.

[20] "Pressurization system for a cryogenic propellant tank in a pressure-fed high altitude rocket" Rob Hersmen and Barry Zandbergen, Deft University of technology, the Netherlands

[21] "Composite materials for cryogenic structures" by M. B. Kasen, National Bureau of Standards, Boulder, Colorado.

[22] "Recent research on cryogenic storage tank: A Review" Pragnesh.D.Kandoliya, Niraj C.Mehta, Vadora institute of engineering,Kotambi,Vadora 